\title{
Nutritional Evaluation of Eating Disorders
}

\author{
Ruiz Prieto Inmaculada \\ Behavioural Sciences Institute, Seville, \\ Spain
}

\section{Introduction}

Eating disorders comprise a group of psychiatric pathologies with an important organic impact, mainly caused by poor eating practices (Miján de la Torre et al., 2006).

In anorexia nervosa, there are a number of anatomical and physiological disturbances resulting from malnutrition. However, it is not usually found malnutrition in case of bulimia nervosa or eating disorders not otherwise specified (EDNOS) with tendency to bulimic behaviours, which can reach slightly higher than normal range of Body Mass Index (Loria \& Gómez, 2010).

Nutritional status is the result between the income and metabolism of nutrients and the nutritional requirements in order to reach a proper growth and maintenance of the normal body's functions (Olveira et al., 2007). When there is not a suitable balance to meet body needs, a process of metabolic adaptation, with major impact on the nutritional status (Jen \& Yan, 2011; Planas et al., 2002), begins.

When the income and metabolism of nutrients is not adequate to the body requirements (what means that there is a negative energy balance), the process of malnutrition begins, facilitating the outcome of eating disorders (Olveira et al., 2007; Planas et al., 2002).

Nutritional status assessment consists of data collection that reveals possible energy and protein deficiencies, as well as any other nutrient deficiency (Olveira et al., 2007).

There are two types of nutritional evaluation, individual and collective. Individual nutritional assessment aims to obtain a defined diagnosis of malnutrition and evaluate the impact of this malnutrition, identifying medical complications. Collective nutritional assessment aims to identify malnourished subjects with potential risk of malnutrition or to make an early detection of malnourished individuals (Lama et al., 2002; Olveira et al., 2007).

In this way, it would be able to qualify and quantify the malnutrition state, which will allow assessing the impact of bad dietary behaviours on the organism, identifying medical complications that can lead to hospitalization. Furthermore, it would be able to determine the nutritional requirements for a proper re-feeding and physical recovery of the subject by determine the appropriate nutritional intervention (Loria \& Gómez, 2010).

To choose the appropriate nutritional intervention it has been used different methods to assess the nutritional status and eating habits. However, since there is no ideal information about collecting methods, it is recommended the use of several markers of nutritional status 
and dietary habits, to compare them with each other and over time. It is important to emphasize that as a greater number of methods used in the nutritional status assessment more information we will have to implement an individualized nutritional treatment, trying to make it more effective. However, as more collecting information methods are used more time and resources are needed (economic, material and professional). To sum up, methods should be chosen according to real possibilities (Planas et al., 2002).

Therefore, nutritional assessment should include medical and dietary history, physical examination, anthropometric measurements and laboratory analysis (Olveira et al., 2007).

\section{Medical and dietary histories}

Eating disorders are complex diseases with a high morbidity and mortality, involving somatic and nutritional impact as a result of poor eating practices (Carrard et al., 2011; Schebendach et al., 2008, 2011).

The etiology of these diseases is also complex and eating disorders have been defined as multifactorial disorders. That make it necessary to acquire as much information as possible in order to implement a complete treatment which includes medical care, nutritional intervention, psychological therapy and health care in order to decrease symptoms as well as to obtain a complete socio-cultural integration, self-care capacity and prevention of relapse or recurrence (Allen et al., 2011; Rosen, 2010; Schebendach et al., 2011).

Therefore, a complete medical history is essential to determine the nutritional status (Castro et al., 2000). It is the first part of the nutritional assessment and it is important to the establishment of the clinician-patient relationship (Huang, 2010).

Clinical interview should include diagnostic criteria for eating disorders and the evaluation of previous treatments (Rosen, 2010). Thus, data of filiation, personal and family disease history, survey of current knowledge about nutrition, bulimic episodes, compensatory behaviors, physical activity and/or exercise, menstrual history, disease awareness and motivation to change will be included in a complete medical history (Loria \& Gómez, 2010).

Personal interviewing is considered the most reliable and valid information collecting method. However, in certain circumstances it is appropriate to obtain information from relatives, as well as the information provided by the person. In eating disorders several factors justify the surrogated interview, as well as the individual. These factors include, on one hand, ignorance of much of the data as well as the inability to express or identify relevant information. In adolescent and infancy period, parents tend to be responsible for the care and feeding of children, so patient does not have the information needed to complete the dietary history.

On the other hand, people with eating disorders hide, voluntarily or involuntarily, certain behaviors as well as temperamental and physical changes during the pathology. It makes necessary to compare the information provided by the patient with that provided by family members (Yago et al., 2002).

Medical history can be structured, semi-structured or free. Structured clinical history presents information to collect step by step. Generally, this type of interview offers closed answers, so the respondent does not provide additional information. 
Semi-structured clinical history involves the most important aspects of eating disorders, although there is the possibility of extending the information according to the interviewer criteria.

Free medical history is totally flexible. It requires an experienced interviewer (with extensive knowledge about eating disorders), who can drive the patient's dialogue to obtain relevant clinical information.

In summary, the clinical history ensures that patient answers, provides security and control to the interviewer over the course of the interview, is flexible to recompile information allowing an individual interview which provides the maximum information that the subject is able to give, except the structured interview that is not flexible. Questions can be complex because the interviewer can solve subject's doubts. However, the realization of medical history requires time and high cost and requires a trained interviewer to maintain a neutral attitude, so that there is no bias in the answers of the respondent. In addition, the interviewer should be formed in the field of eating disorders so it could be collected relevant data to deal with this pathology (Planas et al., 2002; Reiter \& Graves, 2010; Yago et al., 2002).

\subsection{Personal data}

Personal data are needed to identify and contact the patient, therefore it is useful to identify socio-familial context. It will collect name, address, age and date of birth, current occupation, studies, couple's relationships, members of the family and, if possible, relations between them. Phone number of the subject and any family member, e-mail address and any other necessary contact information should be written in the medical history. All of this provides a slight idea of family economic opportunities, relationships and family structure, job integration and interpersonal relationships (Jáuregui, 2006).

\subsection{Personal medical history}

There is a controversy about whether pregnancy and childhood data should be collected or not. However, in childhood period it would be appropriate to collect data on pregnancy, breastfeeding and growth that could explain the current nutritional status of the subject (Lama et al., 2002).

As consequence, characteristics and complications of pregnancy, such as intrauterinemalnutrition and alcohol, drugs or tobacco mother's consumption during pregnancy should be collected. Mothers' nutritional status during pregnancy and after childbirth and mothers' dieting in this time are collected in the medical history. Subsequently, some baby's characteristics will be collected such as weight, height and circumference of the newborn after childbirth. In addition, it must be picked up the period of breastfeeding, lasting and characteristics of this period, baby's appetite and behaviour during meals, mother-child relationship, as well as the food's introduction chronology and family meal introduction.

Additionally, personal medical history must include suffered diseases (especially those related to food), such as cardiovascular disease, diabetes, allergies or food intolerances. All of them must be supported by specific medical diagnosis.

Finally, it is essential to make a present's illness history which collect the triggering factors considered by the subject, previous diagnosis, evolution of the pathology, previous 
treatments, well-being of the patient related to the disease, changes in lifestyle, sociocultural role of the disease, mental and emotional reaction of the patient with the illness (Jáuregui, 2006; Planas et al., 2002).

\subsection{Family medical history}

Taking into account the genetic component in the development of eating disorders as well as the tendency to maintain a certain weight, it is interesting to collect the history of family illnesses, especially related to eating disorders and psychological pathologies like depression, anxiety, personality disorders and organic illness such as cardiovascular disease, diabetes, cancer or obesity (Planas et al., 2002).

\subsection{Nutritional interview}

It is the main part of the clinical history for nutritional status assessment which not only collects the quantitative and qualitative characteristics of the subject's food intake but also the eating habits and the specific environment during meals (Loria \& Gómez, 2010).

It should be taken into account that data provided by respondents are subjective, so the indicated eating habits might not be real (Yago et al., 2002).

Number of meals per day will show if there are restrictions for any of the recommended intakes (usually 5: breakfast, mid-morning, lunch, tea time and dinner), if so it can be seen which meal is restricted and why. With respect to meals' schedule, it is important to know if it is organized or not, rigid or flexible. A proper schedule is appropriate for metabolic activity, so these data are useful for the therapeutic approach. In addition, it could provide data on the possible evolution of the disease, because usually the more restrictive profile are organized and inflexible whereas those profiles of purging eating disorders tend to be erratic and very flexible (Loria \& Gómez, 2010; Schebendach et al., 2008). Intakes' place register provides information if the person usually eats at home or regularly has out-home meals and provides information if intakes are made in a dining room or in any other room. If the person eats sitting, foot or lying down, so treatment based on postural corrections might be necessary to facilitate digestion and food intake. In addition, it is important to collect if intakes are performed accompanied by relatives or alone or if there is some entertainment while the person eats, which could prevent the detection of satiety signals.

Moreover, meals can be structured or disorganized. For lunch and dinner, it is necessary to know if they consist of a single course or two courses, if it is accompanied with bread, if dessert is often eaten and if dessert is eaten before or after meals. Although it would be answered if the person drinks while eating or otherwise reserves the drink for before or after the food intake. Usually, people with eating disorders have inaccurate cognitions about food and usually manifest them through altered eating behaviours (Jáuregui \& Bolaños, 2010).

Preferences and food dislikes, as well as the reason for this must be collected in the nutritional interview. Also, it is appropriate to record preferences and dislikes in culinary techniques. It is interesting for a proper nutritional treatment to know the changes in food tastes of the person from the onset of the disease. It is important to know the personal assessment given to the food, if the person finds it something necessary, compulsory, pleasant, unpleasant and, especially, how the perception has changed of the food with the evolution of the pathology. 
Hunger, satiety and appetite perceptions are altered so it is appropriate to collect the capacity of the differentiation of these sensations in people with eating disorders, as well as the perception of the quantities of food, why it is recommended to write down if the subject is responsible of its food, if it ends the amount served or if it returns to serve more quantity.

Many times patients suffering from an eating disorder are concerned about eating practices of their relatives and are dedicated to select, plan, buy and prepare food for the family. One of the consequences of malnutrition is the emergence of obsessions and occasionally also compulsions, so it is necessary to recognize rituals related to food and abnormal eating behaviors as hide, shredding or cutting food excessively (Jáuregui, 2006). Furthermore, nutritional survey must collect emotional irritability, anxiety or aggression when the person with eating disorder eats or before eating time and if eating with the family is avoided. The food survey should also include bowel habits (Loria \& Gómez, 2010).

In addition, one of the factors present in the development and maintenance of eating disorders is the realization of restrictive diets to reduce weight so nutritional interview should contain information on the realization of such diets under supervision of professionals or at the sole discretion of the person (Kontic et al., 2010).

\subsection{Bulimic episodes}

It is very important to explore the presence of bingeing. Medical history oriented to nutritional status assessment in eating disorders must be based on the kind of food eaten and the approximate food intake volume to check whether the binge episodes are subjective or objective. Precipitating factors of the overeating, features, frequency and location as well as the feelings of the person who suffers them should be recognized (Kontic et al., 2010; Loria \& Gómez, 2010).

\subsection{Compensatory behaviours}

To learn about the potential physical impacts of altered behaviors present in eating disorders it is necessary to register the presence of vomits as well as the use-abuse of laxatives, diuretics or drugs that promote weight loss.

Medical history must show the frequency, characteristics, and feelings of the subject before these purging behaviors as well as if the compensatory behaviours are linked to binge eating (Killen et al., 1986; Loria \& Gómez, 2010).

\subsection{Physical activity}

Many people with eating disorders present severe hyperactivity focused on day-to-day tasks in an extreme way. However, physical exercise in order to loose weight is a typical behavior of eating disorders patients (Killen et al., 1986).

To perform an adequate dietetic treatment it is necessary to pick up the physical exercise practice as well as the daily physical activity (Bratland-Sanda et al., 2010). Excess or defect of physical activity may explain part of the energy balance, negative or positive, respectively. 
In addition, it should be included the sleeping and resting habits, i.e. hours of sleep, if sleep is restful, resting at night, as well as there is resting after meals (Misra \& Klibanski, 2010; Tong \& D’Alessio, 2011).

\subsection{Weight history}

Medical history must collect the minimum and the maximum weights as well as the normal person's weight in order to obtain the amount of weight lost or weight gained and the period of time in which the weight has changed.

On the one hand, it is appropriate to examine whether the undernourished person tolerates weight gain and, on the other hand, if he/she would support that change. In addition, weight history covers the wish of the person to loose weight even when it is well nourished or malnourished (Jáuregui, 2006; Loria \& Gómez, 2010).

\subsection{Menstrual history}

One of the metabolic adaptations present in patients with altered nutritional status is the involvement of the hypothalamus-pituitary-gonad axis, so it is necessary that clinical history collects information about menstruation characteristics, its regularity, menarche age, amenorrhea periods, sexual and reproductive function and use of oral contraceptives or hormone replacement therapy (Chou et al., 2011; Loria \& Gómez, 2010; Misra \& Klibanski, 2010).

\subsection{Psychosocial history}

The social impact of the pathology, interpersonal relationships, family relationships and couple relationships as well as leisure activities give relevant information to choose the appropriate nutritional intervention (Jáuregui, 2006).

\subsection{IIIness knowledge}

It is essential to determine the patients' disease knowledge and motivational state to change, because if the patient does not recognize its altered behaviours as an illness it is very difficult to change them (Loria \& Gómez, 2010). Therefore, when setting the nutritional treatment it is important to know if the person is motivated to change (von Wietersheim \& Hoffmann, 2011).

\section{Physical examination}

As a result of malnutrition, certain dietary practices or compensatory behaviors, common in patients with eating disorders, different clinical signs and medical complications are usually developed, which can be distinguished by the simple observation of the patient, accompanied by certain measures (Olveira et al., 2007).

It should be noted that clinical manifestations that results from malnutrition depends on various factors such as age, sex and the evolution and severity of the eating disorder (Lama et al., 2002). 
The observation of an emaciated or edematous aspect leads to suspect the presence of marasmus or kwashiorkor. These are two types of malnutrition, the first is a type of malnutrition by calorie deficiency and the second by protein deficiency (Loria \& Gómez, 2010; Planas et al., 2002), and even there are mixed kinds of malnutrition. Eating disorders usually presents marasmus because they decrease daily energy intake reducing lipids and carbohydrates consumption but maintaining, to some extent, the protein intake (Loria \& Gómez, 2010).

Observing skin abnormalities, dryness, swelling, dermatitis, skin atrophy, cyanosis of the sacral parts, livid distal extremities or body hair reflecting energy and nutritional deficiencies can be detected. Sometimes, it is possible to detect Acanthosis nigricans in people who binge, which makes suspect the existence of hyperinsulinism. Carotenodermia may appear as a result of hepatic metabolism alterations. Sometimes, people with eating disorders feel cold, particularly referred to their extremities. Pale mucous membranes may reflect anemia whereas the hair weakness may indicate protein deficiencies. Russell's sign as a result of self-induced vomiting, dental erosion, decay, discoloration of the teeth, tooth sensitivity, mouth dry, halitosis, cold sores or parotid gland hypertrophy can be found (Lama et al., 2002; Loria \& Gómez, 2010).

Gastrointestinal signs may appear as delayed gastric emptying which tends to pursue with early satiety, constipation, diarrhoea, gastric dilatation, ulceration esophageal or gastric, haematemesis, colonic dysfunction or rectal prolapse (Lama et al., 2002; Loria \& Gómez, 2010).

Sensory and reflexes capacity may decrease as the involvement of the nervous system because of the under nutritional status (Lama et al., 2002; Loria \& Gómez, 2010).

\section{Anthropometric measurements and body composition}

Malnutrition induces changes in body composition, so assessing those changes would provide information on the nutritional status of the person (Bellido et al., 2002; Misra \& Klibanski, 2010).

However, there are no ideal nutritional evaluation methods. On the one hand, malnutrition itself afflicts the determination of physical parameters. On the other hand, the values found with body measures are compared with reference values to determine the nutritional status of the person while these reference values are not always reliable for the person. The ideal is to compare the values obtained with the body composition measurement of the person with initial values of the own person to assess nutritional status change (Bellido et al., 2002).

Anthropometric parameters give information on the compartments and body structure through the measure of the size and proportions of the body (Bellido et al., 2002; Olveira et al., 2007).

Generally, anthropometric parameters are easy to obtain and are not very expensive but require specific materials such as clinical balance, stadiometer, skin folds and millimeter precision gauge. The collection of these measures requires trained personnel, especially for the obtaining of the skin folds and corporal perimeters (Bellido et al., 2002; Loria \& Gómez, 2010). 


\subsection{Height, weight and body mass index}

These are the measures most used in the assessment of nutritional status especially because the ease to obtain them. However, they are bit sensitive for the early detection of malnutrition (Loria \& Gómez, 2010; Olveira et al., 2007).

They are indicators of lean and fat compartments, so that a weight lost or gain exaggerated in the adult is indicative of malnutrition, while the delay in growth and weight gain in children would be indicative of malnutrition (Olveira et al., 2007).

\subsubsection{Height}

Height is measured using a millimeter precision stadiometer with the person's back to the vertical stem. The person must be barefoot, with the heels together, its arms relaxed and the position of its head should be one in which the auditory meatus and lower orbit eye are horizontal (Bellido et al., 2002; Loria \& Gómez, 2010).

Sometimes the measure of the size cannot be carried out in a conventional manner, this would be the case of elderly or unable to stand or get straight youth. In this case, one can measure the height of the knee, while the patient is in supine decubitus with flexed knee forming a right angle with the leg and level planting at a right angle. Through predictive formulas, it is possible to find the height of people aged between 60-80 years:

$$
\begin{aligned}
& \text { Height }(\mathrm{cm}): 64.19-[0.04 \times \text { age }(\text { years })]+[2.02 \times \text { height of the knee }(\mathrm{cm})] \\
& \text { Height }(\mathrm{cm}): 84.88-[0.24 \times \text { age }(\text { years })]+[1.83 \times \text { height of the knee }(\mathrm{cm})]
\end{aligned}
$$

1 Men height (Bellido et al., 2002; Olveira et al., 2007)

2 Women height (Bellido et al., 2002; Olveira et al., 2007)

If the person cannot maintain the bent leg, one can measure the length from the top edge of the patella to the lower edge of the external maleolo, and it is possible to calculate the size by using the formula:

Height $(\mathrm{cm})$ : [knee height- external maleolo $(\mathrm{cm}) \times 1.121]-[0.117 \times$ age (years) $]+119.6$

Height $(\mathrm{cm})$ : [knee height- external maleolo $(\mathrm{cm}) \times 1.263]+[0.159 \times$ age (years) $]+107.7$

3 Men height (Bellido et al., 2002; Olveira et al., 2007)

4 Women height (Bellido et al., 2002; Olveira et al., 2007)

\subsubsection{Weight}

Weight must be assessed in a clinical scale with the patient in a straight position, look upwards and heels together. It should take place barefoot and with light clothing. It is appropriate that patients do not know the weight in order to not encourage unrest in eating disorders (Loria \& Gómez, 2010).

This measure by itself has no value as determinant of nutritional status, however it is very suitable as a percentage of weight lost, percentage of ideal weight and as a follow-up of the evolution of the physical status of the person (Bellido et al., 2002; Loria \& Gómez, 2010; Olveira et al., 2007). 
Weight loses reliability when edema is present in the person (Loria \& Gómez, 2010; Olveira et al., 2007).

\subsubsection{Ideal weight}

There are tables of ideal weight depending on age, sex and complexion. This measure provides an overall idea of the nutritional status of the person. However, it should be noted that reference tables are not validated for the people we are trying to. However, weighing less than $10 \%$ of the ideal weight is considered underweight (Bellido et al., 2002; Loria \& Gómez, 2010).

Furthermore, it is not appropriate to speak of ideal weight to a population that is especially concerned about their weight.

The percentage of ideal weight is calculated:

$$
\text { \% Ideal weight: [current weight }(\mathrm{kg}) / \text { ideal weight }(\mathrm{kg})] \text { x } 100
$$

5 Bellido et al., 2002

\subsubsection{Weight lost}

Weight lost exceeding $10 \%$ of initial weight in a period less than six months is associated with alterations in body composition with high risk for complications, so it reflects an altered nutritional status (3.; Loria \& Gómez, 2010). The same applies to serious weight lost exceeding $2 \%$ in a week, $5 \%$ in a month, and $7.5 \%$ in three months (Gil et al., 2002; Olveira et al., 2007).

However, these figures are not reliable with the presence of edema or the increase of the total body water, since it hides current lost of muscle mass and fat mass (Bellido et al., 2002).

To calculate the percentage of weight lost, the first thing is to estimate the usual weight that is the weight that the person usually has under normal circumstances and in a stable situation (Bellido et al., 2002).

\% Weight lost: [(usual weight $(\mathrm{kg})$ - current weight $(\mathrm{kg}))$ / usual weight $(\mathrm{kg})]$ x 100

6 Bellido et al., 2002; Loria \& Gómez, 2010

\subsubsection{Body Mass Index}

Although the Body Mass Index (BMI) is related to the percentage of weight lost it is a little sensitive indicator to the early detection of malnutrition. It is estimated a $21 \%$ sensitivity and $95 \%$ specificity in the determination of malnutrition by BMI (Olveira et al., 2007).

It is calculated by a formula relating weight and height:

$$
\text { BMI: current weight }(\mathrm{kg}) / \text { current height }^{2}(\mathrm{~m})
$$

7 Bellido et al., 2002; Loria \& Gómez, 2010; Olveira et al., 2007

The World Health Organization has determined ranges to indicate the nutritional status of adults until the age of 65 using Body Mass Index. In this way: 


\begin{tabular}{|r|l|}
\hline \multicolumn{1}{|c|}{ BMI } & \multicolumn{1}{|c|}{ Malnutrition } \\
\hline $18.5-24.9$ & Well-nourished \\
\hline $17-18.4$ & Low malnourished \\
\hline $16-16.9$ & Moderated malnourished \\
\hline$<16$ & High malnourished \\
\hline
\end{tabular}

Table 1. Malnutrition degree based on the Body Mass Index according to the World Health Organization

However, although a BMI equal to 18.5 is considered as a lower limit of well-nourished people, usually people with a BMI lower than 20 already reflect some degree of malnutrition. From 18.5, each drop of one point of the BMI is associated with a decrease of $5 \%$ of body weight, in the same way that each point greater than 18.5 is associated with increase of $5 \%$ of body weight (Bellido et al., 2002; Loria \& Gómez, 2010).

Nonetheless, BMI is not a good indicator of the nutritional status of persons under 18 years, due to the rate of growth and development, percentile with respect to the normal population will reflect the nutritional status in this period. The limitation of the use of percentile is the acquisition of reference tables validated in the study population (Lama et al., 2002; Nicholls et al., 2002; Olveira et al., 2007). It should be taken as normal the percentiles of 5-95, while focusing on the 50 percentile (Lama et al., 2002).

\subsection{Skin folds}

Being concerned that over $50 \%$ of total body fat is located in the subcutaneous tissue, the extent of skin folds is adequate to determine the fat depletion degree and fluctuations in body fat (Bellido et al., 2002; Loria \& Gómez, 2010; Olveira et al., 2007).

However, the extent of skin folds presents some limitations such as low reproducibility, the need for trained personnel for its measurement and the necessity of assessment based on reference values (Olveira et al., 2007).

Skin fold must be assessed in the non-dominant side. It is estimated the approximate point where the measurement must be carried out and take the crease with thumb and index fingers of left hand separating the muscle layer through lateral movements.

Once caught the skin fold, it is placed the gauge of skin folds at the bottom of the fingers without releasing the fold to measure.

This measurement should be made three times and the average value of three measures will be used. For each measurement the process should start again. The gauge must not be removed since the skin fold is measured so not appear bruise by pressure.

Skin folds values are expressed in millimetres (Loria \& Gómez, 2010).

\subsubsection{Tricipital skin fold}

It is the skin fold most used in clinical practice.

Before proceeding to the measurement, the midpoint of the arm must be found, which is located at the average distance between the acromiun and olecranun. This fold is measured vertically, on the back of the arm, above the midpoint of the arm. 
Arms must be relaxed and extended (Bellido et al., 2002; Loria \& Gómez, 2010; Olveira et al., 2007).

\subsubsection{Bicipital skin fold}

It is measured the same way as the tricipital skin fold but in the anterior face of the arm (Bellido et al., 2002; Loria \& Gómez, 2010; Olveira et al., 2007).

\subsubsection{Subscapular skin fold}

It is measured diagonally from the lower angle that forms the scapula. The arms should be relaxed and extended and the person must be by feet (Bellido et al., 2002; Loria \& Gómez, 2010; Olveira et al., 2007).

\subsubsection{Suprailiac skin fold}

It is measured obliquely, in the midline of the front-top iliac crest. The person should be standing by feet and relaxed (Bellido et al., 2002; Olveira et al., 2007).

\subsubsection{Body fat mass}

It is the estimated percentage of total body fat mass through a combination of measurement of the different skin folds by comparison with reference tables or by predictive equations:

$$
\begin{aligned}
& \% \text { Body fat mass: tricipital skin fold + bicipital skin } \\
& \text { fold + subscapular skin fold + front-top iliac skin fold }
\end{aligned}
$$

8 Durnin y Womersley equation (Loria \& Gómez, 2010)

However, there are many predictive equations to estimate body fat mass through the use of skin folds (Kehoe et al., 2011).

\subsection{Body perimeters}

TThey are measured by means of millimeter gauge.

Body perimeters are not very reliable measures since alterations in the hydration state, body composition and the presence of oedema influence their values.

Moreover, these measures have low reproducibility, on the one hand because they depend on much of the realise personnel and, on the other hand, because the interpretation of the results as an indicator of nutritional status must be based on reference tables, which are not usually appropriate for eating disorders (Bellido et al., 2002).

\subsubsection{Waist-Hip perimeter}

One of the most commonly used indices has been the waist-hip index, employed as an indicator of the location of adipose tissue in the body.

Thus, a central location of adipose tissue has been related to increased risk for cardiovascular disease and metabolic alterations. 
However, there are several studies, which have not found a relationship between the waisthip index and visceral adipose tissue. Moreover, this measure may be influenced by external to the adipose tissue factors (Bellido et al., 2002). So, today, it is not widely used.

$$
\text { Waist-Hip Index: waist (cm) / hip (cm) }
$$

9 Gil et al., 2002

\begin{tabular}{|r|l|l|}
\hline & Central obesity & General obesity \\
\hline Men & W-H I $>0.95$ & W-H I $\leq 0.95$ \\
\hline Women & W-H I $>0.80$ & W-H I $\leq 0.80$ \\
\hline
\end{tabular}

Table 2. Waist-Hip Index (W-H I)

\subsubsection{Brachial circumference}

Comparing the brachial circumference value with references tables related to a particular population results in proper information about the body fat mass and lean body mass, especially in terms of muscle mass (Bellido et al., 2002; Loria \& Gómez, 2010; Olveira et al., 2007).

The professional has to find the average distance between the olecranun and acromiun and go around the arm with a millimeter gauge. The arm must be straight and relaxed and it must be measured in the non-dominant arm (Bellido et al., 2002).

\subsubsection{Muscular arm circumference}

Using the measure of the tricipital fold (TF) and the brachial circumference (BC), the muscle circumference of the arm (MCA) can be estimated. However, the obtained value must be compared with reference tables to estimate whether the muscle circumference of the arm corresponds to the average of the population (Bellido et al., 2002; Loria \& Gómez, 2010; Olveira et al., 2007) or not.

$$
\text { MCA: [0.314 x TF }(\mathrm{cm})]-\mathrm{BC}(\mathrm{cm})
$$

10 Bellido et al., 2002; Loria \& Gómez, 2010; Olveira et al., 2007

\subsubsection{Arm muscle area}

The arm muscle mass can be estimated using the value of the muscle circumference of the arm (MCA) and tricipital fold (TF) under the belief that the arm is circular:

$$
\text { AMA: [MCA - TF }(\mathrm{cm})]^{2} / 4
$$

11 Bellido et al., 2002; Loria \& Gómez, 2010; Olveira et al., 2007

\subsection{Body composition}

To estimate the body composition, a set of sophisticated measures is needed. This is due to the difficulties of anthropometric measures, especially in people with diseases such as obesity or eating disorders, which usually have hidroelectrolytic and body compartments alterations (Bellido et al., 2002; Olveira et al., 2007). 
In order to determine body composition many measurement's methods are based on the "four-compartments body model". The first level is the atomic level, consisting of those elements that compound the $98 \%$ of body weight, which are oxygen, carbon, hydrogen, nitrogen, calcium, phosphorus, potassium, sodium and chlorine. The second level is the molecular one and consists of four compartments: water, proteins, minerals and fat. The third level, called cell model, includes the cell mass, extracellular liquid, adipose tissue and skeletal tissue. The fourth level includes muscle and visceral mass, adipose tissue, and bones (Bellido et al., 2002; Olveira et al., 2007).

Approximately, it is estimated that water represents $60 \%$ of the total body weight of a normnourished human. The muscle mass is $15-20 \%$, and fat mass is $20-25 \%$ and $30-35 \%$ in men and women respectively. Nevertheless, these values depend on the characteristics of the population (Olveira et al., 2007).

\subsubsection{Bone densitometry}

It is based on the Archimedes' principle which indicates that the volume of a body is equal to the volume of water that the body moves, dividing the body into two compartments, fatty and lean, and calculating the body composition according to the density of each compartment (Bellido et al., 2002).

This method is little used in determining body composition. Nevertheless, bone mineral densitometry is essential in eating disorders (Castro et al., 2000; Winston et al., 2008).

Nutritional deficiencies and hormonal alterations presented in patients with eating disorders, especially with a diagnosis of anorexia nervosa, lead the appearance of osteopenia or osteoporosis (Lawson et al., 2010).

It is very important the diagnosis and early treatment of these complications in order to normalize the bone mineral density level and to avoid large decreases in bone mass because although they improve with the re-nutrition, all the lost bone mineral density cannot be recovered. Subsequently, in order to check the evolution of bone mineral density recovery it is necessary to repeat this test during the treatment and not doing it only at the beginning as nutritional evaluation assessment (Mehler et al., 2011). However, it seems that men with osteopenia will recover all of the bone mineral density lost (Castro et al., 2002).

These complications are the most frequent and they are the most relevant among puberal and prepuberal adolescents (Turner et al., 2001).

\subsubsection{Bioelectrical impedance}

Bioelectrical impedance is a method to analysis body composition that is based on the resistance that provides water and body tissues to the course of an electric current determined by the water and electrolytes contained in the different body compartments (Bellido et al., 2002; Olveira et al., 2007; Talluri et al., 1999).

At low frequency current it reflects the extracellular fluid while at high frequency currents it penetrates in the intracellular layer and reflects the total body water. Lean mass is related to the total body water so that it can be calculated. Body fat mass is obtained subtracting the weight of the fat-free mass with respect to the total body weight. 
Body composition is obtained through prediction equations for a specific population that take into account weight, age and sex of the person (Mika et al., 2004).

The possible errors derived from the estimation of body composition by bioelectrical impedance are similar to those obtained by means of the anthropometric methods so there seems to be no advantages in its use (Hannan et al., 1990). However, these mistakes are similar to those committed by other measurement methods that are more expensive and to some extent more difficult to realize (Hannan et al., 1990; Kerruish et al., 2002).

One advantage of the bioelectrical impedance is the determination of the intracellular and extracellular composition, one of the most sensitive indexes of the malnutrition's state (Talluri et al., 1999). In the estimation of the total body water the bioelectrical impedance is suitable (Scalfi et al., 1999) due to the existence of hydrolytic alterations in eating disorders. Usually, patients with anorexia nervosa have a high percentage of total body water that increases with the re-nutrition. Then total body water level normalizes (Mika et al., 2004; Mocanu et al., 1997; Vaisman et al., 1988).

Since the bioelectrical impedance measurement is based on the total body water resistance it is very sensitive to hydrolytic alterations. However, in people over-hydrated it would be estimated an increase in the basal metabolic rate autonomous of anabolism and upside down, in dehydrated people it would be estimated a decrease in the basal metabolic rate self-determined to catabolism. For this reason it seems that the estimation of body fat mass would be blighted by variations in body water (Birmingham et al., 1996). Generally, body composition methods overestimate body fat mass (Haas et al., 2009).

Otherwise, it does not seem that neither bioelectrical impedance analysis nor anthropometric measurements are reliable in people with BMI below 15 (Piccoli et al., 2005).

In contrast, during re-nutrition, body composition changes appear more frequently than weight changes so bioelectrical impedance reflects them (Mika et al., 2004; Olveira et al., 2007; Scalfi et al., 1999).

In summary, the reliability of body composition assessment by bioelectrical impedance analysis is ambiguous although the use of multi-frequency phase-sensitive bioelectrical impedance is appropriate to determine both the energy needs of patients with eating disorders and body composition. The phase-angle measurement does not use predictive formulas and it is used as an indicator of the intracellular and extracellular water and the integrity of cell membranes (Mika et al., 2004; Olveira et al., 2007).

Main advantages of this method are that it is a non-invasive, economic and quick method to determine body composition (Hannan et al., 1990; Mika et al., 2004).

In order to reduce bioelectrical impedance analysis' error it is appropriate to standardize a suitable protocol thus it requires that the person will be in supine position on a nonconductive surface, it must have members in a $45^{\circ}$ abduction, barefoot, fasting for more than two hours, not having made strenuous physical exercise in the last 24 hours, have urinated thirty minutes before the test and not have ingested alcohol, coffee, soft drinks with caffeine or chocolate in the last 24 hours. Also, the person may not be on premenstrual and menstrual period and not to use metal fittings during the test. The bioelectrical impedance must be at room temperature but not extreme (Loria \& Gómez, 2010). 


\subsubsection{Other methods}

There are other methods of body composition analysis less used in the clinical practice of eating disorders because they are more costly and difficult to implement.

In addition most of them require specific materials and more time to realize.

\subsubsection{Isotopic methods}

Isotopic methods are relatively simple techniques that consist of administering radioactive isotopes, typically deuterium $\left({ }^{2} \mathrm{H}\right)$, tritium $\left({ }^{3} \mathrm{H}\right)$ or oxygen-18 $\left({ }^{18} \mathrm{O}\right)$, to measure the dilution and thus calculate total body water and extracellular fluid. Subsequently, predictive formulas are used to find the fat mass and lean body mass.

Another method is the radiation measurement of an isotope of potassium $\left({ }^{40} \mathrm{~K}\right)$ to mediate the total body potassium. This potassium isotope is directly associated with the fat-free mass so after getting its value one subtract the lean mass weight to the total body weight as fat mass is obtained.

They are methods that require specific devices that make them difficult to realize in the clinical practice (Bellido et al., 2002; Olveira et al., 2007).

\subsubsection{Absorciometry}

Absorciometry analyses body composition by dividing the body into three compartments via the absorption of $\mathrm{x}$-rays. It is especially important in determining bone mineral density in the presence of osteoporosis but it is an expensive method that requires complex equipment found only in certain hospitals (Bellido et al., 2002).

\subsubsection{Ultrasonography}

Subcutaneous fat is measured through the application of perpendicular ultrasonic waves on the surface of the skin with ultrasonografic methods. Considering the clinical practice, it is a non-wide applicable technique due to its high cost (Bellido et al., 2002; Olveira et al., 2007). In addition, it does not seem an adequate application in eating disorders (DiVasta et al., 2007).

\subsubsection{Nuclear magnetic resonance}

Nuclear magnetic resonance is a non-invasive and highly targeted technique focused on the first body level called atomic level. It measures the ability of atomic nuclei in the absorption of certain frequency energy when they are subjected to a magnetic field.

Due to its high cost and time required to realize, nuclear magnetic resonance has short interest in the clinical practice. However, it is a useful tool to determine changes in cellular metabolites without biopsies (Bellido et al., 2002; Olveira et al., 2007).

\subsubsection{Computerized axial tomography}

Computerized axial tomography analyses body composition at the tissue level according to the density of different tissues. It is a very precise technique but little representative of nutritional status that would be appropriate to determine the visceral fat mass in very malnourished patients (Bellido et al., 2002; Olveira et al., 2007). 


\section{Laboratory analysis}

Biochemical data are analysed to obtain information on the nutritional status and possible metabolic disturbances in eating disorders (Bellido et al., 2002; Loria \& Gómez, 2010). However, it should be taken into account that the nutrients' serum level does not indicate their deposits' state, because that depends on the homeostatic regulation and food intake, as well as the individual malnutrition's adaptation (Loria \& Gómez, 2010).

In explanation, biochemical parameters are little sensitive and little specific by determining the nutritional status as well as little reproducible.

However, it is often found a nearly normal biochemical profile in eating disorder patients. So it is rarely found hypoproteinaemia, albumin is usually normal and, occasionally, they are elevated serum cholesterol levels which leads to suspicion of alterations in lipid metabolism, commonly in those with eating disorders who have amenorrhea. Also, HDLcholesterol values are usually high while triglycerides are usually low, possibly as a result of hipoestrogenism and decreased thyroid function. Sometimes there is hypoalbuminaemia at the beginning of the re-nutrition, which must be taken into account with respect to a possible refeeding syndrome (Olveira et al., 2007; Loria \& Gómez, 2010).

Normocytic and normochromic anaemia can be found in malnourished eating disorder patients. Thus, the presence of ferropenic anaemia is rare because the absence of menstruation compensates the reduced iron's intake.

Lymphopenia and thrombocytopenia can appear in severe malnourished people.

\subsection{Proteins}

It is assumed that serum proteins decrease corresponds to a decreased hepatic synthesis, which may reflect the visceral protein mass depletion. However, in the amount of serum protein, factors as the rate of metabolism, protein degradation, hydration degree, concentration and amount of extracellular fluid or in hospitalized patients, administration of serum or plasma (Bellido et al., 2002; Olveira et al., 2007) play a relevant role.

As a consequence of metabolic adaptation and body composition alterations, protein synthesis markers are not useful in the determination of the nutritional status (Loria \& Gómez, 2010) in eating disorder patients.

\subsubsection{Albumin}

Albumin measurement is a nonspecific marker of nutritional status, which does not reflect acute nutritional changes as a result of its long half-life (18-20 days) and its high body pool $(4-5 \mathrm{~g} / \mathrm{kg})$.

It is considered that $2.8-3.5 \mathrm{~g} / \mathrm{dL}$ plasma levels reflect slight malnutrition, $2.1-2.7 \mathrm{~g} / \mathrm{dL}$ reflect moderate malnutrition and $<2.1 \mathrm{~g} / \mathrm{dL}$ indicates severe malnutrition. However, serum albumin decreases may reflect specific pathological states or homeostatic regulations (Bellido et al., 2002; Olveira et al., 2007).

Hipoalbuminaemia is not usually found (Bellido et al., 2002;Loria \& Gómez, 2010; Olveira et al., 2007) even in anorexia nervosa. 


\subsubsection{Transferrin}

Transferrin is an iron transporter protein. Despite its short half-life (8-10 days) and its low plasma pool $(5 \mathrm{~g})$ is not a good indicator of nutritional status in patients with eating disorders. Its level may be altered as a result of specific pathologies and can be found elevated in the presence of iron deficiencies and with estrogenic treatment (Bellido et al., 2002; Olveira et al., 2007).

However, it is described that plasma level of $150-175 \mathrm{mg} / \mathrm{dL}$ indicates slight malnutrition, plasma level of $100-150 \mathrm{mg} / \mathrm{dL}$ indicates moderate malnutrition and plasma level $<100 \mathrm{mg} / \mathrm{dL}$ shows severe malnutrition (Bellido et al., 2002).

\subsubsection{Pre-albumin}

Prealbumin is a protein that binds to thyroxine (T3) so that is very sensitive to metabolic stress. It has a short half-life (2-3 days) and it is considered to be a good marker of acute nutritional changes but in eating disorders it is not very useful (Bellido et al., 2002; Olveira et al., 2007).

Normal values are estimated between 17 and $20 \mathrm{mg} / \mathrm{dL}$. Therefore, levels of $10-15 \mathrm{mg} / \mathrm{dL}$ would indicate slight malnutrition; levels of $5-10 \mathrm{mg} / \mathrm{dL}$ would indicate moderate malnutrition; and levels $<5 \mathrm{mg} / \mathrm{dL}$ would reflect severe malnutrition (Bellido et al., 2002; Olveira et al., 2007).

\subsubsection{Retinol binding protein}

Retinol binding protein presents a very short half-life (10 hours), which makes it a good marker of acute nutritional changes but it is very sensitive to stress. In addition, in eating disorders it is usually altered the level of vitamin A as a result of lipid metabolism alterations, which makes retinol binding protein be an non-good indicator of nutritional status (Bellido et al., 2002; Loria \& Gómez, 2010; Olveira et al., 2007).

Its short half-life makes it a marker no useful enough for clinical practice. Even so, their plasma reference values are 2.6-7.6mg/dL (Bellido et al., 2002; Olveira et al., 2007).

\subsubsection{Insulin-like growth factor 1 (IGF1)}

Insulin-like growth factor coupled with its transport protein has a half- life of 3-18 hours, which makes it to have little clinical use. It depends on human growth hormone and the energy intake levels so that its value is usually altered in eating disorders (Loria \& Gómez, 2010; Olveira et al., 2007).

\subsubsection{Creatinine/height index}

Creatinine/height index would serve as muscle mass depletion indicator although it depends on the kidney and liver function and it is altered by the use of diuretics and highprotein diets, which reduces its usefulness in the nutritional evaluation of eating disorders.

It has also a little clinical use index because it is necessary the collection of 24-hour urine during 3 consecutive days and, in addition, reference tables are necessary to evaluate it (Bellido et al., 2002). 


\subsubsection{Nitrogen balance}

Nitrogen balance represents the difference between the ingested and the excreted nitrogen and it is used as an indicator of protein turnover.

In a healthy subject, nitrogen balance should be equal to zero. Thus, a nitrogen balance $<0$ indicates a catabolic state or an inadequate protein intake. Nitrogen balance between 0 and 5 indicates a moderate level of catabolism while less than -5 values indicates a severe degree of catabolism. However, eating disorder patients often keep high-protein diets, which may hinder this parameter's validity (Bellido et al., 2002; Olveira et al., 2007).

A predictive equation that uses the urine ureic nitrogen as total ureic nitrogen is used to calculate nitrogen balance because the real value of total ureic nitrogen is very complex. In addition, this equation does not take into account the nitrogen's lost by skin and stool which is estimated to be between 2-3g (Bellido et al., 2002; Olveira et al., 2007).

$$
\text { Nitrogen balance: (ingested protein g / 6.25) - (urine urea g + 4) }
$$

12 Bellido et al., 2002; Olveira et al., 2007

\subsubsection{Immunity test}

Some alterations with regards to the lymphocyte population and hypersensitivity have been observed in malnourished people. However, eating disorder patients rarely suffer infections till the last evolutional stages of the disease, which could be due to cortisol, cytokines and leptin alterations (Bellido et al., 2002; Loria \& Gómez, 2010; Olveira et al., 2007).

\subsubsection{Account and lymphocyte function}

It is considered normal a number of lymphocytes $>1500$ cells $/ \mathrm{mm}^{3}$. A lymphocytes account between 1500-1200cells $/ \mathrm{mm}^{3}$ could indicate a slight malnutrition. A range between 1200800 cells $/ \mathrm{mm}^{3}$ usually reflects a moderate malnutrition, and a severe malnutrition may be reflected by $<800$ cells $/ \mathrm{mm}^{3}$.

In addition, lymphocyte function usually decreases (Bellido et al., 2002; Loria \& Gómez, 2010; Olveira et al., 2007).

\subsubsection{Delayed hypersensitivity}

It is not a specific test to know the nutritional status since it can be influenced by many factors.

Delayed hypersensitivity consists of injecting different antigens intra-skinny, which the subject has been previously sensitized. The immune system acts and shows a skin's induration of $>5 \mathrm{~mm}$ during the subsequent $24-72$ hours.

In malnutrition states this reaction is committed (Bellido et al., 2002; Olveira et al., 2007).

\section{Determination of energy requirements}

Before the nutritional approach in eating disorders, it is essential to estimate the energy requirements of the subject according to his/her nutritional status (Klein et al., 2011) that would be beneficial to normalize the weight (Krahn et al., 1993). 
In anorexia nervosa, the re-nutrition period is very dangerous because high energy intakes can trigger altered physiological responses, which can lead to a refeeding syndrome (Birmingham et al., 2005; Forman-Hoffman et al., 2006). Therefore, a progressively increase in the diets' energy density is required (Birmingham et al., 2005; Cuerda et al., 2005; Gentile et al., 2010; Scalfi et al., 2001; Schebendach et al., 1995).

Nutritional requirements are directly related to the basal metabolic rate, which is often diminished in anorexia nervosa and augmented in bulimia nervosa (Hlynsky et al., 2005; Nicholls et al., 2002; Russell et al., 2001; Scalfi et al., 2010; Schebendach et al., 1997; Sedlet et al., 1989). However, anorectic patients tend to present high respiratory coefficient and induced thermogenesis, which may explain the high weight reduction in emaciated patients and the difficulties to recovery and maintain a healthy weight (Russell et al., 2001).

Similarly, it is necessary to determine the energy requirements in eating disorder patients with overweight/obesity (Kushner \& Drover, 2011).

There are different methods to determine the energy requirements: empirically, using predictive equations, indirect calorimetry and bioelectrical impedance (Schebendach et al., 1995).

\subsection{Empirical method}

It consists of the prescription of a well-known energy diet and it is based on the evolution of the nutritional status and the presence of symptoms related to the refeeding syndrome. Taking into account these two factors, changes in the energy density of the initially prescribed diet will be introduced.

In clinical practice this is the gold standard to determine the energy requirements (Schebendach et al., 1995). In addition, it seems the most appropriate method to determine the energy requirements to gain weight since there is no other method to quantify it (Birmingham et al., 2005). In overweight or obese patients it is usually indicated some restrictive diets because there are no specific guidelines to determine the energy requirement for the weight normalization (Kushner \& Drover, 2011).

\subsection{Predictive equations}

After the empirical method to determine the energy requirements in eating disorders, this is the second most used one in clinical practice due to its speed and ease (Loria \& Gómez, 2010).

Different types of predictive equations can be used, although all of them have an error rate, and only some of them have been validated to be applied in eating disorders (Kushner \& Drover, 2011).

\subsubsection{Harris-Benedict equation}

Harris-Benedict equation is used to determine the basal energy expenditure in healthy adults (BEE) expressed in kilocalories per day (Scalfi et al., 2010). This formula is not adequate to estimate the energy requirements in eating disorders, obesity or adolescents although it is the most commonly used in clinical practice (Klein et al., 2011; Scalfi et al., 2010). 
It seems that this equation overestimates the energy requirements in undernourished people while it underestimates the energy requirements because eating disorder patients increase the energy requirements during re-nutrition (Cuerda et al., 2005; Krahn et al., 1993; Marra et al., 2002; Schebendach et al., 1997). It only appears to be appropriate when the weight normalization and stabilization in eating disorders (Forman-Hoffman et al., 2006).

However, even taking into account the error, its application does not seem to be very wrong (Schebendach et al., 1995).

Men BEE: $66.47+[13.75 \times$ weight $(\mathrm{kg})]+[5 \times$ height $(\mathrm{cm})]-[6.75 \times$ age (years) $]$

Women BEE: $665.1+[9.56 \times$ weight $(\mathrm{kg})]+[1.85 \times$ height $(\mathrm{cm})]-[4.68 \times$ age (years) $]$

13 Harris-Benedict equation (Loria \& Gómez, 2010)

\subsubsection{Owen equation}

Owen equation appears to be appropriate to estimate the basal energy expenditure (BEE) in healthy Caucasian women and women who practice restrictive diets (Siervo et al., 2003).

It seems adequate to calculate the basal metabolic rate in anorectic patients since the beginning of treatment until the normal weight restoration (Forman-Hoffman et al., 2006).

$$
\begin{aligned}
& \text { Men BEE: } 879+[10.2 \times \text { weight }(\mathrm{kg})] \\
& \text { Women BEE: } 795+[7.18 \times \text { weight }(\mathrm{kg})]
\end{aligned}
$$

14 Owen equation (Loria \& Gómez, 2010)

\subsubsection{Miffin-St. Joer equation}

Similarly to Owen predictive equation it is appropriate to calculate the basal metabolic rate in anorexia nervosa since the beginning of treatment until several weeks of re-nutrition (Forman-Hoffman et al., 2006).

Men BEE: $5+[10 \times$ weight $(\mathrm{kg})]+[6.25 \times$ height $(\mathrm{cm})]-[5 \times$ age $($ years $)]$

Women BEE: $161+[10 \times$ weight $(\mathrm{kg})]+[6.25 \mathrm{x}$ height $(\mathrm{cm})]-[5 \times$ age (years) $]$

15 Miffin-St. Joer equation (Loria \& Gómez, 2010)

\subsubsection{World Health Organization (WHO), Food and Agriculture Organization (FAO) and United Nations Organization (ONU) equations}

Like the rest of predictive equations they usually overestimate the basal energy expenditure in eating disorders (Cuerda et al., 2005; Marra et al., 2005).

\subsubsection{Schebendach equation}

It is the only equation focused on anorexia nervosa, which is a correction of the HarrisBenedict predictive equation that allow to be applied it in adolescents with anorexia nervosa. However, it is not appropriate for anorectic patients over than 18 years (Marra et al., 2005; Scalfi et al., 2010). 


\begin{tabular}{|r|c|l|}
\hline \multirow{2}{*}{$\begin{array}{c}\text { Age } \\
\text { (years })\end{array}$} & \multicolumn{2}{|c|}{ Malnourished level } \\
\cline { 2 - 3 } & Men & Women \\
\hline $0-3$ & {$[60.9 \times$ weight $(\mathrm{kg})]-54$} & {$[61.0 \times$ weight $(\mathrm{kg})]-51$} \\
\hline $3-10$ & {$[22.7 \times$ weight $(\mathrm{kg})]+495$} & {$[22.5 \times$ weight $(\mathrm{kg})]+499$} \\
\hline $10-18$ & {$[17.5 \times$ weight $(\mathrm{kg})]+651$} & {$[12.2 \times$ weight $(\mathrm{kg})]+746$} \\
\hline $18-30$ & {$[15.3 \times$ weight $(\mathrm{kg})]+679$} & {$[14.7 \times$ weight $(\mathrm{kg})]+496$} \\
\hline $30-60$ & {$[11.6 \times$ weight $(\mathrm{kg})]+879$} & {$[8.7 \times$ weight $(\mathrm{kg})]+829$} \\
\hline$>60$ & {$[13.5 \times$ weight $(\mathrm{kg})]+487$} & {$[10.5 \times$ weight $(\mathrm{kg})]+596$} \\
\hline
\end{tabular}

Table 3. Basal Energy Expenditure (kilocalories per kilogram)

$$
\operatorname{BMR}(\mathrm{kJ} / \text { day })=148.3+91.5 \times \text { weight }(\mathrm{kg})
$$

16 Schebendach equation (Scalfi et al., 2001)

\subsection{Indirect calorimetry}

Indirect calorimetry is a non-invasive and low-cost method used to determine the basal metabolic rate that provides information to raise an adequate nutritional intervention and monitoring eating disorder patients (Dragani et al., 2006; Hlynsky et al., 2005; Scalfi et al., 2010; Schebendach et al., 1995).

It is appropriate for both patients with anorexia nervosa and with bulimia nervosa, as well as for binge eating disorder patients (Cuerda et al., 2005; Schebendach et al., 1995).

In addition, the continuous metabolic changes faced by people with eating disorders justify the use of this method (Schebendach et al., 1997). Furthermore the additional use of anthropometric measurements allows the adaption of the nutritional therapy to the patient's evolution (Dragani et al., 2006).

\subsection{Bioelectrical impedance}

Bioelectrical impedance is appropriate to calculate the basal metabolic rate in anorexia nervosa taking into account its limitations as a result of hydration alterations (Marra et al., 2005).

\section{Food choice in eating disorder patients and relatives}

\subsection{Food choice in eating disorders}

It is difficult to learn about eating habits in eating disorder patients especially because the usual data collection system has been based on the amount of intake and not on the quality of the food choice in these people (Banna et al., 2010). Nowadays, a low nutritional variety is associated with a poor prognosis of the pathology (Loria et al., 2009; Schebendach et al., 2008; Steinhausen et al., 2002).

One analysis of the dietary choice in patients with eating disorders shows a trend to choice little varied, low energy density menus with protein excess and fat deficiencies (Jáuregui \& Bolaños, 2009; Loria et al., 2009; Loria \& Gómez, 2010; Schebendach et al., 2008; Steinhausen et al., 2002). 
It seems that people with anorexia nervosa tend to maintain certain dietary behaviors and to modify others following the usual patterns of the socio-cultural context (Jáuregui \& Bolaños, 2009).

Moreover, there are differences in the intake of the different food groups. It seems that people with bulimia nervosa choose less bread and cereals than patients with anorexia nervosa, although people with anorexia nervosa choose less bread, cereals, meat, sausages, fatty, and fried foods, than people without eating disorders do (Jáuregui \& Bolaños, 2009; van der Ster Wallin et al., 1995).

\subsection{Relatives food choice's influence in eating disorder patients}

Originally relationship between family and eating disorders has been studied on the basis of family relationships and family structures or genetics. However, it is increasingly more remarkable that food attitudes, implementation of physical activity and self-care, even health knowledge in relatives influence directly on behaviour and cognitions in their children (Hendrie et al., 2011).

Eating habits, as well as different foods tastes start to develop since the early childhood. It is believed that babies are born with a natural ability to control intake depending on their energy needs. This ability is developed and maintained over time through adequate education and training, however, it is lost when the baby is not able to learn to distinguish hunger and satiety sensations. For example while artificial bottled eating (Gregory et al., 2010; Ruiz, 2011; Savage et al., 2007).

Furthermore, parents act as a behavioral eating pattern (modelling) for their children, being responsible to choose different foods, elaborate and provide them while feeding and socialize the child in the eating behaviour, which should be maintain during its lifetime. So parents influence children's future preferences. So similar food preferences and intakes characteristics are distinguished between mothers and their children as discovering more frequently daughters that make energy restrictive diets when their mothers are chronic dieters and intake's control problems in daughters whom parents also have (Brunstrom et al., 2005; Ruiz, 2011). It seems that when children are overweight or obese their parents act restricting and controlling their feeding thus promoting hidden intakes in the absence of hunger (Faith et al., 2008).

In this way, certain emotional relations with food appear depending on the mother's behavior and displays of affection received by the mother from breastfeeding. Even more it seems as negative factors in the eating disorders development, those families, which give too much importance to weight, caloric intake value, families where one parent is a chronic dieter, those in which parents have intake's control problems and those with unstructured meals (Ruiz, 2011).

Emotional eating is a complex set of behaviors and cognitions involved in the development and maintenance of eating disorders (Ricca et al, 2011).

Benefits of relatives' inclusion in the treatment of patients with eating disorders are well described in order to provide them with strategies for management of the pathology and as support in the acquisition of new habits of life (Cairns et al., 2007; Ruiz, 2011; Treasure et al., 
2011). However, it have not been studied the benefits of carrying out nutritional education and healthy habits acquisition in relatives of eating disorder patients (Ruiz, 2011).

Generally, relatives' food choice trend to be low caloric diets with protein and fat excess but carbohydrate deficiency. Lipid profile in dietary choice of relatives of eating disorder patients seems to be unbalanced, with saturated and monounsaturated fatty acids excess, cholesterol excess and polyunsaturated and essential fatty acids deficiency. In addition, it presents under contribution to the requirements of calcium, magnesium, zinc, iodine, fluorine, folic acid and vitamin D and does not comply with the recommendations of food consumption frequency. This shows that dietary choice of relatives of patients with eating disorder does not constitute a healthy food choice pattern (Ruiz, 2011).

Nevertheless, it should be taken into account that food choice depends on the population and more studies are needed to obtain more consistency data.

\section{Questionnaires}

The difficulty of collecting information about food habits and cognitions justify the use of questionnaires (Olveira et al., 2007).

\subsection{4-hour dietary recall}

The 24-hour dietary recall is the most used method for the current intake's nutritional evaluation as its ease and low cost needs to implementation (Greger \& Etnyre, 1978; Yago et al., 2002). Generally, it requests the patient to fill out the survey with all the food eaten and beverages drank during the last 24 hours.

It provides information on the amount, type of food consumed, elaborating methods used, ingredients of the dish made and hours of consumption to know the intakes' structure (Anselmo et al., 1995; Yago et al., 2002).

Nevertheless, it must be noted that the reliability of this questionnaire is affected by the memory capacity of the patients, its capacity of description and its concern about the intake so that greater attention paid to food greater capacity to complete the questionnaire adequately. The 24-hours dietary recall is usually fulfilled by mothers, in case of children under 12 years old (Anselmo et al., 1995).

If the patients know previously that it is going to make this questionnaire and the presence of the interviewer may vary the characteristics of the diet written down so it results somewhat healthier than it was, really. Foods most frequently omitted in the 24-hour recall are sauces and condiments.

It is very important that the interviewer is trained in nutrition especially to estimate the ingested quantities.

Advantages of 24-hour recall are that it does not modify the usual intake of the respondent and that it is a fast, simple, low-cost method, as it requires little effort by the respondent. However, it does not provide information about eating habits since it only includes one day and depends on the ability of memory and expression capacity of the patient. The 24-hour recall shows a higher energy intake than the real although its adequacy to the real intake is 
intermediate between that reflects the dietary record and food frequency intake's questionnaire (Prentice et al., 2011). It is a validated nutritional assessment method but the estimation of nutrient intake should not be based on it (Greger \& Etnyre, 1978).

The less reliable data obtained from the 24-hour recall is the portion of food intake, vegetables being the worst reflected amounts (Souverein et al., 2011). In addition, the amount of intake often appears overestimated in malnourished children (Anselmo et al., 1995).

\subsection{Dietary record}

The dietary record consists of writing down the meals and drinks ingested over a period of time ranging from 1 to 7 days. Data should be described carefully and completely, structured in five meals per day and including all the food used in the preparation of a dish. In this way, the dietary record shows the food frequency consumption, meals' structures, diet variety and quality of dietary choice (Yago et al., 2002).

The ingested amounts can be estimated by different methods. It can be estimated by double weight, in explain weigh food to eat and then weigh leftovers. Also, the amount of food intake can be estimated by recording the usually cooking measurement used, in example a spoon, a plate, a saucepan, or a ladle (Yago et al., 2002).

In anorexia nervosa the dietary record shows a higher energy intake than real but it reflects properly lipid and caloric profile and micronutrient consumption (Hadigan et al., 2000). Food attitudes affect the appropriateness of the dietary record's registration. Thus, in obese people that restrict their food intake the questionnaire shows lower energy than the real while it resembles reality in those with emotional intake or large numbers of intakes away from home, in restaurants (Vansant \& Hulens, 2006). Furthermore, women's dietary records show lower energy intake than real more frequently than men (Asbeck et al., 2002).

Nonetheless, the weekly intake registered in the dietary record fits adequate with the energy requirements obtained by indirect calorimetry (Vansant \& Hulens, 2006).

During childhood, the reliability of the dietary records is related with the cognitive ability, and girls usually have greater skill at any age, probably by being more aware with food (Smith et al., 2011).

The advantages of this questionnaire are the possibility of nutritional current intake assessment and knowledge of the nutritional habits. Disadvantages are the potential bias made in the implementation of the register, the requirement of a high collaboration and the possibility of habits' modification (all proving that the intake must be evaluated by a professional). Double weighing registration requires a high effort but is the most exact while the estimate record there may be an error in the estimation (Gil et al., 2002).

\subsection{Food frequency questionnaires}

A food frequency questionnaire aims to obtain the frequency of consumption of the different foods or groups of them.

It does not offer quantitative information about the intake, nor provides knowledge about the eating habits of the person who complete the questionnaire (Taylor et al., 2009). 
However, it provides global information referring to large periods of intake (Yago et al., 2002).

Anyway, the questionnaire can be quantitative when moreover to frequency of consumption it shows the amount of food ingested, semi-quantitative when the list of foods expresses the amount of the ration or qualitative which does not include the amount of food or portion size (Yago et al., 2002). Of all the most used is the semi-quantitative food frequency questionnaire which is suitable for groups of food consumption (Vázquez et al., 2011).

Some of the advantages of this questionnaire are its low cost, the short time required to complete it, the ease of encoding data and, finally the fact that it does not change the eating habits of the patient. However, its reliability depends on the memory and synthesis capacity of the user and the information provided is limited because it depends on the list of foods that the questionnaire presents. Nevertheless, this list of foods also provides an advantage because one can select groups or types of food on the basis of the nutrient or nutrients on which want to get more information. For this reason, this type of questionnaires must always be validated (Yago et al., 2002).

One of the most important aspects in the nutritional treatment of patients with anorexia nervosa is to ensure an adequate consumption of calcium and vitamin D to encourage correct bone mineralization improving or preventing the onset of osteopenia. In relation to this, a questionnaire of frequency of food intake that determines the amount of calcium and vitamin D in these patients has been validated (Taylor et al., 2009).

In clinical practice, a way to obtain reliable and complete information about the patient's intake is to combine data obtained through a questionnaire of frequency food intake, with a 24-hour dietary recall and various nutritional markers which are mentioned above (Freedman et al., 2011).

\subsection{Food craving inventory}

The experience of the craving involves behavioural and emotional aspects as well as cognitive. So it would be the feeling of a high desire to eat a certain type or group of food with great difficulty to resist (Jáuregui et al., 2010).

This feeling is very present in eating disorders and appears to be related with other psychopathological aspects like depression or anxiety issues. However, craving should not be understood as a feeling characteristic of eating disorders because it appears in the general population.

Even so, craving has been related to the presence of bulimia nervosa or purging-type eating disorders. Correlating the food craving inventory with other eating disorder inventories one gets relationship between craving and bulimia, although it must be taken into account that not all people who crave manifest overeating episodes. It is appropriate to use the food craving inventory in patients with obesity and binge eating disorder who shows greater desire for sweet food (White \& Grilo, 2005).

Craving relates to bulimia nervosa, binge eating disorder or obesity. Moreover it is associated with premenstrual syndrome and seasonal affective disorder. Also, food craving inventory correlates with a high concern about weigh, awareness-raising by the food 
restriction, fear of gaining weight and body dissatisfaction which are characteristic factors of eating disorders (Jáuregui et al., 2010).

Data obtained in relation to restrictive diets and hunger with presence of craving are ambiguous, existing studies that confirm the relationship while others finding it not to exist (Jáuregui et al., 2010).

Then, women experience more craving than men although there are differences in the type of food they desire. Thus, women show greater attraction for sweets and -trans fats which is especially observed in foods such as chocolate, while men prefer high caloric density food or fast food and saturated fat. There are no differences according to sex in the attraction of carbohydrates and proteins.

The Spanish version of the Food Craving Inventory has undergone some changes in the list of foods and food types deleted because they were not object of craving in that sociocultural context (Jáuregui et al., 2010).

\subsection{Irrational food beliefs scale}

The irrational food beliefs scale measures cognitive distortions, attitudes and unhealthy beliefs in relation to food (Osberg et al., 2008). These cognitions and behaviors are associated to thoughts about weight or body image and related to phobias, stress and internalization of the current body aesthetic model (excessively thin), all present in eating disorders. Furthermore, these cognitions help to keep the intake of low-calorie diets as a means to regulate weight and food intake (Jáuregui \& Bolaños, 2010).

The questionnaire has two factors, one of irrational beliefs associated with cognitive distortions, beliefs and attitudes to food altered and one of rational beliefs which is associated with healthy eating based on recommendations of current nutritional guidelines (Jáuregui \& Bolaños, 2010).

Irrational food beliefs are associated to bulimic symptoms like overeating or impulses control as well as the realization of low-calorie diets in obese population (Jáuregui \& Bolaños, 2010; Osberg et al., 2008).

\subsection{Food choice questionnaire}

The acquisition of healthy eating habits begins in a good food choice. Socio-cultural level influence food choice as well as personal preferences so it will influence food choice, the inhabited country, ethical aspects, socio-economic level or sensory aspects of food, among other things.

The presence of psychopathology affects the food choice and it is related to a higher level of irrational ideas relative to food. As greater irrational ideas related to food greater ready-toeat food would be chosen. Concern about weight, tendency to have a muscular body low in fat and preference for low energy density foods does not appear only in women as men show great concern for that which shows that cultural qualities influence food choice.

\subsection{Eating attitudes test}

The objective of the Eating Attitudes Test is to know attitudes relative to food in patients with anorexia nervosa. 
The original version features 40 items while there is an abbreviated version of 26 items, which has a high correlation with the original (Castro et al., 1991; Garner \& Garfinkel, 1979; Garner et al., 1982; Mateos et al., 2010; Orbitello et al., 2006).

This questionnaire shows high specificity and sensitivity to recognize people with characteristics of anorexia nervosa or bulimia nervosa although it is not sensitive to distinguish between anorexia nervosa and bulimia nervosa (Castro et al., 1991; Garner \& Garfinkel, 1979; Garner et al., 1982).

However, it shows three main factors, one shows food restriction and does not display differences between anorexia nervosa and bulimia nervosa. A second factor indicates bulimia and concern for food, and a third factor reflects self-control related to food and perception of social concern about weight gain. It seems that people with anorexia nervosa score lowest in factor 2 and highest in factor 3 than people with bulimia nervosa (Castro et al., 1991; Garner et al., 1979; Garner et al., 1982).

An advantage of this questionnaire is the sensitivity to symptomatic changes reaching normal scores in patients who suffered anorexia nervosa and that do not currently suffer (Castro et al., 1991; Garner et al., 1979; Garner et al., 1982).

\section{Difficulties in the registration of the ingested food quantities and knowledge of dietary habits: new technologies}

One of the most difficult data to obtain reliably with the food survey is the amount of food ingested. There are various methods to estimate the food quantity consumed although there is not an ideal measure.

The use of standardized rations is not appropriate because it depends on the geographical area and even in the cooking utensils employed in each house (Yago et al., 2002).

Usually the amount of food ingested has been estimated through cooking utensils employed, in example spoon, plate, glass, and so on. And then, a professional trained in the field of food is responsible for estimating the real amount ingested. So it is a method of very low-cost and easy but unreliable especially in eating disorders where the ingested amounts are very altered (Yago et al., 2002).

Another method is the uses of 3D models or measurement photographs but these is not appropriate in clinical practice and less in eating disorders taking into account the difficulties in their perception of the amount of food (Yago et al., 2002).

Estimate the amount consumed in grams by the person is not valid in the nutritional survey insofar it is usually an elevated error in the estimation (Yago et al., 2002).

Double weighing method, in explain, weighing food to served on the plate before eating and then weigh the leftovers, is very reliable. However, it is not recommended for patients with eating disorders, which are already quite concerned about the amount and volume of food they eat. Furthermore, it is a costly method by the time it requires (Loria \& Gómez, 2010; Yago et al., 2002). 
Nonetheless, it is complex to collect information on the personal eating habits since methods of collecting information, in example the dietary record always have an error that they depend on the capabilities of the person who completes it (Matthiessen et al., 2011).

Currently, the reliability of the data collected increases in terms of amount of food ingested and eating habits through the use of digital photography and video.

The combination of estimating dietary record with digital photographs of meals, before and after eating them to assess the amount served and leftovers, is a suitable method to learn about eating habits of the person and it has shown internal reliability (Matthiessen et al., 2011).

Moreover, displaying behaviors and reactions, both of people suffering from eating disorders as of their families, are very helpful when it comes to know eating habits and behaviors altered during meals. It could prove helpful in guiding the nutritional treatment of patients with eating disorders (Cairns et al., 2007).

\section{Conclusions}

Nutritional evaluation consists of data collection to determine the nutritional status of the patient.

The knowledge of the malnutrition's characteristics permits to evaluate the impact in the organism of the unhealthy diet patterns in eating disorders, as well as to determine the nutritional requirements for a proper physical recovery.

However, there is no ideal nutritional status assessment's method as it is recommended to compare different systems.

Nevertheless, it should be taken into account that the more number of methods used are, the more will be the time and cost to complete the nutritional evaluation of the patient.

Summarising, the information collecting methods should be chosen according to their real possibilities but getting as more information as possible in order to make the nutritional treatment individualized and more effective.

Therefore, a complete medical history is essential to obtain information about the patient. It should include personal data, personal medical history, family medical history, nutritional interview and it should be focused on the eating disorders diagnostic criteria as bulimic episodes, compensatory behaviours, physical activity, weight history, menstrual history, psychosocial history and illness knowledge.

However, medical history would provide subjective information so physical examination and body composition measurements are needed to complete the nutritional evaluation.

Physical examination is based in well-known clinical signs and medical complications caused by unhealthy diets. It depends on the age and sex of the patient even the severity of the pathology and the type of malnutrition. In anorexia nervosa malnutrition is usually marasmus because of the daily energy intake restriction.

Body composition measurements are difficult and anthropometric measurements or body composition sophisticated systems can be applied. 
Anthropometric measurements are skin folds and body perimeters measures that provide information on the nutritional status of the patient by comparing its values with reference tables or by predictive equations. Eating disorders deal with the problem that malnutrition influences the determination of the physical parameters and neither reference tables nor predictive equations are validated in such people.

Body Mass Index is one of the anthropometric measures more used in clinical practice because its ease to do. Nonetheless, it is a little sensitive measure of malnutrition and it is not adequate in people under 18 years old. Tricipital skin fold is also very used in the clinical practice.

In eating disorder patients bone mineral densitometry is necessary to know the mineralization state of the bones and to monitoring the bone mass recovering.

It results ambiguous the use or not of bioelectrical impedance in the body composition determination in eating disorders. However, it should make the same error rate than anthropometric measures and it is easily to realize. Nevertheless, multi-frequency phasesensitive bioelectrical impedance seems to be adequate in eating disorders because it deal with hydrolytic alterations of these patients.

There are other body composition measurement methods but they are not used in clinical practice because of their high cost.

Laboratory analyses are not very proper nutritional evaluation markers because it is usually found an almost normal biochemical profile in eating disorder patients.

Something else in the nutritional evaluation of eating disorder patients is the energy requirements' determination. The empirical method is the most used in clinical practice followed by predictive equations methods. However, there are no predictive equations validated in eating disorders, except the Schebendach, but it is only validated in adolescents with anorexia nervosa. Furthermore, there are no predictive equations to know the energy requirements to gain or lose weight, if it is necessary.

Indirect calorimetry is a good method to know the basal metabolic rate in eating disorders and multi-frequency phase-sensitive bioelectrical impedance is a good predictor in anorexia nervosa.

Nowadays, it is not only important to know the intake quantity. The quality of food choice is a good profile marker in eating disorders. Moreover, parental eating behaviours may affect the nutritional choice and preferences of their children so it would be appropriate to know about the eating habits in relatives of patients.

To complete the nutritional evaluation, some questionnaires providing information on the amount and type of food eaten, presence and intensity of craving and irrational food beliefs are used in eating disorder patients. The same applies to attitudes relative to food in anorexia nervosa patients.

Finally, the combination of 24-hour recall, dietary record and questionnaire of frequency of food intake besides digital photograph and video provides reliably information about the amount of food ingested and eating habits. 


\section{Acknowledgement}

I would like to thank Ignacio Jáuregui for his excellent teaching methods focused in eating disorders as well as patients and their relatives for allow me to learn more and more about these disorders.

\section{References}

Allen, KL., Fursland, A., Watson, H. \& Byrne, SM. (2011). Eating disorder diagnoses in general practice settings: comparison with structured clinical interview and selfreport questionnaires. Journal of Mental Health, Vol.20, No.3, pp. 270-280, ISSN 13600567

Anselmo, Mt., Gomes, C., Barros, FC. \& Petrucci D. (1995). Twenty-four-hour recall overestimates the dietary intake of malnourished children. The Journal of nutrition, Vol.125, No.4, (April 1995) pp.880-884, ISSN 1541-6100

Asbeck, I., Mast, M., Bierwag, A., Westenhöfer, J., Acheson, KJ., Müller, MJ. (2002). Severe underreporting of energy intake in normal weight subjects: use of an appropriate standard and relation to restrained eating. Public health nutrition, Vol.5, No.5, (October 2002) pp. 683-690, ISSN 1475-2727

Banna, JC., Vera, LE., Kaiser, LL. \& Townsend, MS. (2010). Using qualitative methods to improve questionnaires for Spanish speakers: assessing face validity of a food behavior checklist. Journal of the American Dietetic Association, Vol.110, No.1, (January 2010) pp.80-90, ISSN 1878-3570

Bellido, D., Carreira, J. \& Martínez, M. (2002). Análisis de la composición corporal, In: Tratado de Nutrición, Gil, A., pp. 149-192, Editorial Panamericana, ISBN 84-88336-438, España

Birmingham, CL., Hlynsky, J., Whiteside, L. \& Geller, J. (2005). Caloric requirement for refeeding inpatients with anorexia nervosa: the contribution of anxiety exercise, and cigarette smoking. Eating and weight disorders, Vol.10, No.1, (March 2005) pp. e6-9, ISSN 1590-1262

Birmingham, CL., Jones, PJ., Orphanidou, C., Bakan, R., Cleator, IG., Goldner, EM. \& Phang, PT. (1996). The reliability of bioelectrical impedance analysis for measuring changes in the body composition of patients with anorexia nervosa. The International journal of eating disorders, Vol.19, No.3, (August 1996) pp. 311-315, ISSN 1098-108X

Bratland-Sanda, S., Sundgot-Borgen, J., Rosenvinge, JH., Hoffart, A. \& Martinsen, EW. (2010). "I'm not physically active - I only go for walks": physical activity in patients with longstanding eating disorders. The International journal of eating disorders,Vol.43, No.1, (January 2010) pp. 88-92, ISSN 1098-108X

Brunstrom, JM., Mitchell, GL. \& Baguley, TS. (2005). Potential early-life predictors of dietary behaviour in adulthood: a retrospective study. International journal of obesity, Vol.29, No.5, (May 2005) pp. 463-474, ISSN 1476-5497

Cairns, JC., Styles, LD. \& Leichner, P. (2007). Evaluation of meal support training for parents and caregivers using a video and a manual. Journal of the Canadian Academy of Child and Adolescent Psychiatry, Vol.16, No.4, (November 2007) pp. 164-166, ISSN 1719-8429

Carrard, I., Crépin, C., Rouget, P., Lam, T., Golay, A. \& van der Linden, M. (2011). Randomised controlled trial of a guided self-help treatment on the Internet for 
binge eating disorder. Behaviour research and therapy, Vol.49, No.8, (August 2011), pp. 482-491, ISSN 1873-622X

Castro, J., Lázaro, L., Pons, F., Halperin, I. \& Toro, J. Predictors of bone mineral density reduction in adolescents with anorexia nervosa. Journal of the American Academy of Child and Adolescent Psychiatry, Vol.39, No.11, (November 2000) pp. 1365-1370, ISSN 1527-5418

Castro, J., Toro, J., Lázaro, L., Pons, F. \& Halperin, I. (2002). Bone mineral density in male adolescents with anorexia nervosa. Journal of the American Academy of Child and Adolescent Psychiatry, Vol.41, No.5, (May 2002) pp. 613-618, ISSN 1527-5418

Castro, J., Toro, J., Salamero, M. \& Guimera, E. (1991). The Eating Attitudes Test: Validation of the Spanish version. Psychological assessment, Vol.7, No.2, pp. 175-190, ISSN 1040-3590

Chou, SH., Chamberland, JP., Liu, X., Matarese, G., Gao, C., Stefanakis, R., Brinkoetter, MT., Gong, H., Arampatzi, K. \& Mantzoros, CS. (2011). Leptin is an effective treatment for hypothalamic amenorrhea. Proceedings of the National Academy of Sciences of the United States of America, Vol.108, No.16, (April 2011) pp. 6585-6590, ISSN 1091-6490

Cuerda, MC., Ruiz, A., Moreno, C., Iriondo, MT., Velasco, C., Bretón, I., Camblor, M. \& García, P. (2005). Study of energy expenditure in anorexia nervosa: agreement between indirect calorimatry and several equations. Nutrición hospitalaria, Vol.20, No.6, (November-December 2005) pp. 371-377, ISSN 1699-5198

DiVasta, AD., Ringelheim, J., Bristol, SK., Feldman, HA. \& Gordon, CM. (2007). Skeletal measurements by quantitative ultrasound in adolescents and young women with anorexia nervosa. The Journal of pediatrics,Vol.150, No.3, (March 2007) pp. 286-290, ISSN 1097-6833

Dragani, B., Malatesta, G., Di Ilio, C. \& De Cristofarok P. (2006). Dynamic monitoring of restricted eating disorders by indirect calorimetry: a useful cognitive approach. Eating and weight disorders, Vol.11, No.1, (March 2006) pp. e9-14, ISSN 1590-1262

Faith, MS., Storey, M., Kral, TV. \& Pietrobelli, A. (2008). The feeding demands questionnaire: assessment of parental demand cognitions concerning parent-child feeding relations. Journal of the American Dietetic Association, Vol.108, No.4, (April 2008) pp. 624-630, ISSN 1878-3570

Forman-Hoffman, VL., Ruffin, T. \& Schultz, SK. (2006). Basal metabolic rate in anorexia nervosa patients: using appropriate predictive equations during the refeeding process. Annals of clinical psychiatry, Vol.18, No.2, (April-June 2006) pp. 123-127, ISSN 1547-3325

Freedman, LS., Schatzkin, A., Midthune, D. \& Kipnis, V. (2011). Dealing with dietary measurement error in nutritional cohort studies. Journal of the National Cancer Institute, Vol.103, No.14, (June 2011) pp. 1086-1092, ISSN 1460-2105

Garner, DM. \& Garfinkel, PE. (1979). The Eating Attitudes Test: an index of the symptoms of anorexia nervosa. Psycholycal Medicine, Vol.9, No.22, pp. 273-279, ISSN 0033-2917

Garner, DM., Olmsted, MP., Bohr, Y. \& Garfinkel, PE. (1982). The Eating Attitudes Test: psychometric features and clinical correlates. Psychological Medicine, Vol.12, pp. 8718, ISSN 0033-2917

Gentile, MG., Pastorelli, P., Ciceri, R., Manna, GM. \& Collimedaglia, S. (2010). Specialized refeeding treatment for anorexia nervosa patients suffering from extreme undernutrition. Clinical nutrition, Vol.29, No.5, (October 2010) pp. 627-632, ISSN 1532-1983 
Greger, JL. \& Etnyre, GM. (1978). Validity of 24-hour dietary recalls by adolescent females. American journal of public health, Vol.68, No.1, (January 1978) pp. 70-72, ISSN 1541-0048

Gregory, JE., Paxton, SJ. \& Brozovic, AM. (2010). Maternal feeding practices, child eating behavior and body mass index in preschool-aged children:a prospective analysis. International Journal of Behavioral Nutrition and Physical Activity, Vol.28, No.7 (June 2010) pp. 55, ISSN 1479-5868

Haas, VK., Kohn, MR., Clarke, SD., Allen, JR., Madden, S., Müller, MJ. \& Gaskin, KJ. (2009). Body composition changes in female adolescents with anorexia nervosa. The American journal of clinical nutrition, Vol.89, No.4, (April 2009) pp. 1005-1010, ISSN 1938-3207

Hadigan, CM., Anderson, EJ., Miller, KK., Hubbard, JL., Herzog, DB., Klibanski, A. \& Grinspoon, SK. (2000). Assessment of macronutrient and micronutrient intake in women with anorexia nervosa. The International journal of eating disorders, Vol.28, No.3, (November 2000) pp. 284-292, ISSN 1098-108X

Hannan, WJ., Cowen, S., Freeman, CP. \& Shapiro, CM. (1990). Evaluation of bioelectrical impedance analysis for body composition measurements in anorexia nervosa. Clinical physics and physiological measurement, Vol.11, No.3, (August 1990) pp. 209216, ISSN 0143-0815

Hendrie, GA., Coveney, J. \& Cox, DN. (2011). Defining the complexity of childhood obesity and related behaviours within the family environment using structural equation modeling. Public health nutrition, Vol.2, (August 2011) pp. 1-10, ISSN 1475-2727

Hlynsky J, Birmingham CL, Johnston M, Gritzner S. (2005). The agreement between the MedGem indirect calorimeter and a standard indirect calorimeter in anorexia nervosa. Eating and weight disorders, Vol.10, No.4, (December 2005) pp. e83-87, ISSN 1590-1262

Huang, CM. \& Hsieh, CJ. (2010). Treating bulimia nervosa: a nurse's experience using cognitive behavior therapy. Hu li za zhi The Journal of Nursing, Vol.57, No.2, (April 2010) pp. S29-34, ISSN 0047-262X

Jáuregui, I. \& Bolaños, P. (2009). Choice of diet in patients with anorexia nervosa. Nutrición Hospitalaria, Vol.24, No.6, (May 2009) pp. 682-687, ISSN 0212-1611

Jáuregui, I. \& Bolaños, P. (2010). Spanish version of the irrational food beliefs scale. Nutrición Hospitalaria, Vol.25, No.5, pp. 852-859, ISSN 0212-1611

Jáuregui, I. (2006). La imagen de una sociedad enferma: anorexia, bulimia, atracones y obesidad (1st Ed.), Grafema, ISBN 84-934225-9-2, España

Jáuregui, I., Bolaños, P., Carbonero, R. \& Valero, E. (2010). Psychometric properties of the Spanish version of Food Craving Inventory (FCI-SP). Nutrición Hospitalaria, Vol.25, No.6, pp. 984-992, ISSN 0212-1611

Jen, N. \& Yan, AC. (2010). Syndromes associated with nutritional deficiency and excess. Clinics in dermatology, Vol.26, No.6, (November-December 2010), pp. 669-685, ISSN 1879-1131

Kehoe, SH., Krishnaveni, GV., Lubree, HG., Wills, AK., Guntupalli, AM., Veena, SR., Bhat, DS., Kishore, S., Fall, CH., Yajnik, CS. \& Kurpad, A. (2011). Prediction of body-fat percentage from skinfold and bio-impedance measurements in Indian school children. European journal of clinical nutrition, (July 2011) ISSN 1476-5640

Kerruish, KP., O'Connor, J., Humphries, IR., Kohn, MR., Clarke, SD., Briody, JN., Thompson, EJ., Wright, KA., Gaskin, KJ. \& Baur, LA. (2002). Body composition in 
adolescents with anorexia nervosa. The American journal of clinical nutrition, Vol.75, No.1, (January 2002) pp. 31-37, ISSN 1938-3207

Killen, JD., Taylor, CB., Telch, MJ., Saylor, KE., Maron, DJ. \& Robinson, DN. (1986). Selfinduced vomiting and laxative and diuretic use among teenagers. Precursors of the binge-purge syndrome?. The journal of the American Medical Association, Vol.255, No.11, (March 1986) pp. 1447-1449, ISSN 1538-3598

Klein, CJ., Villavicencio, SA., Schweitzer, A., Bethepu, JS., Hoffman, HJ. \& Mirza, NM. (2011). Energy prediction equations are inadequate for obese Hispanic youth. Journal of the American Dietetic Association, Vol.111, No.8, (August 2011) pp. 12041210, ISSN 1878-3570

Kontic, O., Vasiljevic, N., Jorga, J., Jasovic-Gasic, M., Lakic, A. \& Arsic, A. (2010). Presence of different forms of compensatory behaviours among eating disorder patients. Srpski arhiv za celokupno lekarstvo, Vol.138, No.5-6, (May-June 2010) pp. 328-332, ISSN 03708179

Krahn, DD., Rock, C., Dechert, RE., Nairn, KK. \& Hasse, SA. (1993). Changes in resting energy expenditure and body composition in anorexia nervosa patients during refeeding. Journal of the American Dietetic Association, Vol.93, No.4, (April 1993) pp. 434-438, ISSN 1878-3570

Kushner, RF. \& Drover, JW. (2011). Current Strategies of Critical Care Assessment and Therapy of the Obese Patient (Hypocaloric Feeding): What Are We Doing and What Do We Need to Do?. Journal of parenteral and enteral nutrition, Vol.1, (August 2011), ISSN 0148-6071

Lama, RA., Codoceo, RE. \& Morais, A. (2002). Valoración del estado nutricional en el niño, In: Tratado de Nutrición, Gil, A., pp. 81-116, Editorial Panamericana, ISBN 84-8833643-8 , España

Loria, V. \& Gómez, C. (2010). Manual teórico-práctico de Educación Nutricional en Trastornos de la Conducta Alimentaria (1st Ed.), EDIMSA, ISBN 978-84-7714-337-6, Madrid, España

Loria, V., Gómez, C., Lourenço, T., Pérez, A., Castillo, R., Villarino, M., Bermejo, L. \& Zurita, L. (2009). Evaluation of the utility of a Nutrition Education Program with Eating Disorders. Nutrición Hospitalaria, Vol.24, No.5, (September-October 2009) pp. 558567, ISSN 1699-5198

Marra, M., De Filippo, E., Signorini, A., Silvestri, E., Pasanisi, F., Contaldo, F. \& Scalfi, L. (2005). Phase angle is a predictor of basal metabolic rate in female patients with anorexia nervosa. Physiological measurement, Vol.26, No.2, (April 2005) pp. S145-152, ISSN 1361-6579

Marra, M., Polito, A., De Filippo, E., Cuzzolaro, M., Ciarapica, D., Contaldo, F. \& Scalfi, L. (2002). Are the general equations to predict BMR applicable to patients with anorexia nervosa? Eating and weight disorders, Vol.7, No.1, (March 2002) pp. 53-59, ISSN 1590-1262

Mateos-Padorno, C., Scoffier, S., Polifrone, M., Martínez-Patiño, MJ., Martínez-Vidal, A. \& Zagalaz, ML. (2010). Analysis of eating disorders among 12-17 year-old adolescents in the island of Gran Canaria. Eating and weight disorders, Vol.15, No.3, (September 2010) pp. e190-194, ISSN 1590-1262

Matthiessen, TB., Steinberg, FM. \& Kaiser, LL. (2011). Convergent validity of a digital imagebased food record to assess food group intake in youth. Journal of the American Dietetic Association, Vol.111, No.5, (May 2011) pp. 756-761, ISSN 1878-3570 
Mehler, PS., Cleary, BS. \& Gaudiani, JL. (2011). Osteoporosis in anorexia nervosa. Eating disorders, Vol.19, No.2, (March 2011) pp.194-202, ISSN 1532-530X

Miján, A., Pérez-García, A., Martín, E. \& de Mateo, B. (2006).Is an integral nutritional approach to eating disorders feasible in primary care? British Journal of Nutrition, Vol.96, No.1, (August 2006), pp.82-85, ISSN 0007-1145

Mika, C., Herpertz-Dahlmann, B., Heer, M. \& Holtkamp, K. (2004). Improvement of nutritional status as assessed by multifrequency BIA during 15 weeks of refeeding in adolescent girls with anorexia nervosa. The Journal of nutrition, Vol.134, No.11, (November 2004) pp. 3026-3030, ISSN 1541-6100

Misra, M. \& Klibanski, A. (2010). Neuroendocrine consequences of anorexia nervosa in adolescents. Endocrine development, Vol.24, No. 17, (November 2010) pp. 197-214, ISSN 1662-2979

Mocanu, V., Zbranca, E., Colev, V. \& Estour, B. (1997). An analysis of the evolution of body compartments in anorexia nervosa--the bioelectrical impedance method. Revista medico-chirurgicală a Societății de Medici şi Naturalişti din Iaşi, Vol.101, No.3-4, (JulyDecember 1997) pp. 83-90, ISSN 0048-7848

Nicholls, D., Wells, JD., Singhal, A. \& Stanhope, R. (2002). Body composition in early onset eating disorders. European journal of clinical nutrition, Vol.52, No.9, (September 2002) pp. 857-865, ISSN 1476-5640

Olveira, G. (2nd Ed.). (2007). Manual de Nutrición Clínica y Dietética, Ediciones Díaz de Santos, ISBN 978-84-7978-806-3, España

Orbitello, B., Ciano, R., Corsaro, M., Rocco, PL., Taboga, C., Tonutti, L., Armellini, M. \& Balestrieri, M. (2006). The EAT-26 as screening instrument for clinical nutrition unit attenders. International journal of obesity, Vol.30, No.6, (June 2006) pp. 977-981, ISSN 1476-5497

Osberg, TM., Poland, D., Aguayo, G. \& MacDougall, S. (2008). The Irrational Food Beliefs Scale: development and validation. Eating behaviors, Vol.9, No.1, (January 2008) pp. 25-40, ISSN 1873-7358

Piccoli, A., Codognotto, M., Di Pascoli, L., Boffo, G. \& Caregaro, L. (2005). Body mass index and agreement between bioimpedance and anthropometry estimates of body compartments in anorexia nervosa. Journal of parenteral and enteral nutrition, Vol.29, No.3, (May-June 2005) pp. 148-156, ISSN 0148-6071

Planas, M., Pérez-Portabella, C. \& Virgili, N. (2002). Valoración del estado nutricional en el adulto, In: Tratado de Nutrición, Gil, A., pp. 117-148, Editorial Panamericana, ISBN 84-88336-43-8, España

Prentice, RL., Mossavar-Rahmani, Y., Huang, Y., Van Horn, L., Beresford, SA., Caan, B., Tinker, L., Schoeller, D., Bingham, S., Eaton, CB., Thomson, C., Johnson, KC., Ockene, J., Sarto, G., Heiss, G. \& Neuhouser, ML. (2011). Evaluation and Comparison of Food Records, Recalls, and Frequencies for Energy and Protein Assessment by Using Recovery Biomarkers. American journal of epidemiology, Vol.15, (July 2011), ISSN 1476-6256

Reiter, CS. \& Graves, L. (2010). Nutrition therapy for eating disorders. Nutrition in Clinical Practice, Vol.25, No.2, (April 2010) pp. 122-136, ISSN 1941-2452

Ricca, V., Castellini, G., Fioravanti, G., Lo Sauro, C., Rotella, F., Ravaldi, C., Lazzeretti, L. \& Faravelli, C. (2011). Emotional eating in anorexia nervosa and bulimia nervosa. Comprehensive psychiatry, (May 2011) pp. 25, ISSN 1532-8384 
Rosen, DS. (2010). Identification and management of eating disorders in children and adolescents. Pediatrics, Vol.126, No.6, (December 2010) pp. 1240-1253, ISSN 1098-4275

Ruiz I. (2011). Elección dietética de familiares de pacientes con trastornos de la conducta alimentaria. Trastornos de la conducta alimentaria, Vol.13, (May 2011) pp. 1384-1415, ISSN 1699-7611

Russell, J., Baur, LA., Beumont, PJ., Byrnes, S., Gross, G., Touyz, S., Abraham, S. \& Zipfel, S. (2001). Altered energy metabolism in anorexia nervosa. Psychoneuroendocrinology, Vol.26, No.1, (January 2001) pp. 51-63, ISSN 1873-3360

Savage, JS., Fisher, JO. \& Birch, LL. (2007). Parental influence on Eating Behavior: Conception to Adolescence. The Journal of law, medicine \& ethics, Vol.35, No.1, (Spring 2007) pp. 22-34, ISSN 1748-720X

Scalfi, L., Marra, M., Caldara, A., Silvestri, E. \& Contaldo, F. (1999). Changes in bioimpedance analysis after stable refeeding of undernourished anorexic patients. International journal of obesity and related metabolic disorders, Vol.23, No.2, (February 1999) pp. 133-137, ISSN 0307-0565

Scalfi, L., Marra, M., De Filippo, E., Caso, G., Pasanisi, F. \& Contaldo, F. (2001). The prediction of basal metabolic rate in female patients with anorexia nervosa. International journal of obesity and related metabolic disorders, Vol.25, No.3, (March 2001) pp. 359-364, ISSN 0307-0565

Schebendach, J., Golden, NH., Jacobson, MS., Arden, M., Pettei, M., Hardoff, D., Bauman, N., Reichert, P., Copperman, N. \& Hertz, S. (1995). Indirect calorimetry in the nutritional management of eating disorders. The International journal of eating disorders, Vol.17, No.1, (January 1995), pp. 59-66, ISSN 1098-108X

Schebendach, JE., Golden, NH., Jacobson, MS., Hertz, S. \& Shenker, IR. (1997). The metabolic responses to starvation and refeeding in adolescents with anorexia nervosa. Annals of the New York Academy of Sciences, Vol.28, No.817, (May 1997) pp. 110-119, ISSN 1749-6632

Schebendach, JE., Mayer, LE., Devlin, MJ., Attia, E., Contento, IR., Wolf, RL. \& Walsh, BT. (2008). Dietary energy density and diet variety as predictors of outcome in anorexia nervosa. The American Journal of Clinical Nutrition, Vol.87, No.4, pp. 810-816, ISSN 1938-3207

Schebendach, JE., Mayer, LE., Devlin, MJ., Attia, E., Contento, IR., Wolf, RL. \& Walsh, BT. (2011). Food choice and diet variety in weight-restored patients with anorexia nervosa. Journal of American Dietetic Association, Vol.111, No.5, pp. 732-736, ISSN 1878-3570

Sedlet, KL. \& Ireton-Jones, CS. (1989). Energy expenditure and the abnormal eating pattern of a bulimic: a case report. Journal of the American Dietetic Association, Vol.89, No.1, (January 1989) pp. 74-77, ISSN 1878-3570

Smith, AF., Baxter, SD., Hardin, JW., Guinn, CH. \& Royer, JA. (2011). Relation of Children's Dietary reporting accuracy to cognitive ability. American journal of epidemiology, Vol. 173, No.1, (January 2011) pp. 103-109, ISSN 1476-6256

Souverein, OW., de Boer, WJ., Geelen, A., van der Voet, H., de Vries, JH., Feinberg, M. \& Van't Veer, P. (2011). Uncertainty in intake due to portion size estimation in 24hour recalls varies between food groups. The Journal of nutrition, Vol.14, No.7, (July 2011) pp. 1396-1401, ISSN 1541-6100 
Steinhausen, HC. (2002). The outcome of anorexia nervosa in the 20th century. The American Journal of Psychiatry, Vol.159, No.8, (August 2002) pp. 1284-1293, ISSN 1535-7228

Talluri T., Lietdke, RJ., Evangelisti, A., Talluri, J. \& Maggia, G. (1999). Fat-free mass qualitative assessment with bioelectric impedance analysis (BIA). Annals of the New York Academy of Sciences, Vol.20, No.873, (April 1999) pp. 94-98, ISSN 1749-6632

Taylor, C., Lamparello, B., Kruczek, K., Anderson, EJ., Hubbard, J. \& Misra, M. (2009). Validation of a food frequency questionnaire for determining calcium and vitamin $\mathrm{D}$ intake by adolescent girls with anorexia nervosa. Journal of the American Dietetic Association, Vol.109, No.3, (March 2009) pp. 479-485, ISSN 1878-3570

Tong, J. \& D'Alessio, D. (2011). Eating disorders and gastrointestinal peptides. Current opinion in endocrinology, diabetes, and obesity, Vol.18, No.1, (February 2011) pp. 42-49, ISSN 1752-2978

Treasure, J., Whitaker, W., Todd, G. \& Whitney, J. (2011). A description of multiple family workshops for carers of people with anorexia nervosa. European eating disorders review, Vol.6, (July 2011), ISSN 1099-0968

Turner, JM., Bulsara, MK., McDermott, DM., Byrne, GC., Prince, RL. \& Forbes, DA. Predictors of low bone density in young adolescent females with anorexia nervosa and other dieting disorders. The International journal of eating disorders, Vol.30, No.3, (November 2001) pp. 245-251, ISSN 1098-108X

Vaisman, N., Corey, M., Rossi, MF., Goldberg, E. \& Pencharz, P. (1988). Changes in body composition during refeeding of patients with anorexia nervosa. The Journal of pediatrics, Vol.113, No.5, (November 1988), pp. 925-929, ISSN 1097-6833

van der Ster Wallin, G., Norring, C., Lennernäs, MA. \& Holmgren, S. (1995). Food selection in anorectics and bulimics: food items, nutrient content and nutrient density. Journal of the American College of Nutrition, Vol.14, No.3, (June 1995) pp. 271-277, ISSN 1541-1087

Vansant, G. \& Hulens, M. (2006). The assessment of dietary habits in obese women: influence of eating behavior patterns. Eating disorders, Vol.14, No.2, (March-April 2006) pp. 121-129, ISSN 1532-530X

Vázquez, C., Alonso, R., Garriga, M., de Cos, A., de la Cruz, J., Fuentes-Jiménez, F., SalasSalvadó, J. \& Mata, P. (2011). Validation of a food frequency questionnaire in Spanish patients with familial hypercholesterolaemia. Nutrition, metabolism, and cardiovascular diseases, Vol.22, (June 2011), ISSN 1590-3729

Von Wietersheim, J. \& Hoffman, C. (2011). Comparison of instruments assessing the readiness to change in patients with anorexia nervosa. Zeitschrift für Psychosomatische Medizin und Psychotherapie, Vol.57, No.1, pp. 62-76, ISSN 1438-3608

White, MA. \& Grilo, CM. (2005). Psychometric properties of the Food Craving Inventory among obese patients with binge eating disorder. Eating behaviors, Vol.6, No.3, (June 2005) pp. 239-245, ISSN 1873-7358

Winston, AP., Alwazeer, AE. \& Bankart, MJ. (2008). Screening for osteoporosis in anorexia nervosa: prevalence and predictors of reduced bone mineral density. The International journal of eating disorders, Vol.41, No.3, (April 2008) pp. 284-287, ISSN 1098-108X

Yago, MD., Martínez, E. \& Mañas, M. (2002). Métodos para la evaluación de la ingesta de alimentos, In: Tratado de Nutrición, Gil, A., pp. 35-74, Editorial Panamericana, ISBN 84-88336-40-3, España 


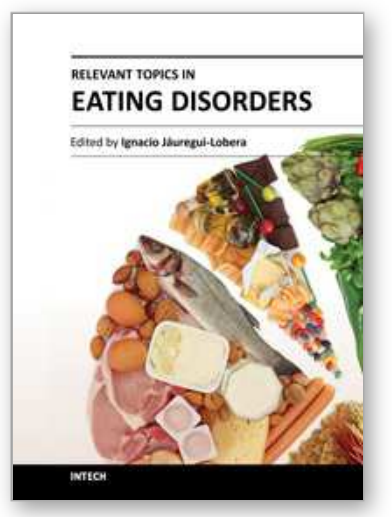

\author{
Relevant topics in Eating Disorders \\ Edited by Prof. Ignacio Jáuregui Lobera
}

ISBN 978-953-51-0001-0

Hard cover, 390 pages

Publisher InTech

Published online 22, February, 2012

Published in print edition February, 2012

Eating disorders are common, frequently severe, and often devastating pathologies. Biological, psychological, and social factors are usually involved in these disorders in both the aetiopathogeny and the course of disease. The interaction among these factors might better explain the problem of the development of each particular eating disorder, its specific expression, and the course and outcome. This book includes different studies about the core concepts of eating disorders, from general topics to some different modalities of treatment. Epidemiology, the key variables in the development of eating disorders, the role of some psychosocial factors, as well as the role of some biological influences, some clinical and therapeutic issues from both psychosocial and biological points of view, and the nutritional evaluation and nutritional treatment, are clearly presented by the authors of the corresponding chapters. Professionals such as psychologists, nurses, doctors, and nutritionists, among others, may be interested in this book.

\title{
How to reference
}

In order to correctly reference this scholarly work, feel free to copy and paste the following:

Ruiz Prieto Inmaculada (2012). Nutritional Evaluation of Eating Disorders, Relevant topics in Eating Disorders, Prof. Ignacio Jáuregui Lobera (Ed.), ISBN: 978-953-51-0001-0, InTech, Available from:

http://www.intechopen.com/books/relevant-topics-in-eating-disorders/nutritional-evaluation-of-eating-disorders

\section{INTECH}

open science | open minds

\author{
InTech Europe \\ University Campus STeP Ri \\ Slavka Krautzeka 83/A \\ 51000 Rijeka, Croatia \\ Phone: +385 (51) 770447 \\ Fax: +385 (51) 686166 \\ www.intechopen.com
}

\author{
InTech China \\ Unit 405, Office Block, Hotel Equatorial Shanghai \\ No.65, Yan An Road (West), Shanghai, 200040, China \\ 中国上海市延安西路65号上海国际贵都大饭店办公楼405单元 \\ Phone: +86-21-62489820 \\ Fax: +86-21-62489821
}


(C) 2012 The Author(s). Licensee IntechOpen. This is an open access article distributed under the terms of the Creative Commons Attribution 3.0 License, which permits unrestricted use, distribution, and reproduction in any medium, provided the original work is properly cited. 